Research Article

\title{
Dynamic Analysis of Retailers' Paid Membership Strategy
}

\author{
Lina $X u \mathbb{D}^{1,2}$ and Zhiqing Meng $\mathbb{D}^{1}$ \\ ${ }^{1}$ School of Management, Zhejiang University of Technology, Hangzhou, Zhejiang, China \\ ${ }^{2}$ Keyi College, Zhejiang Sci-Tech University, Hangzhou, Zhejiang, China \\ Correspondence should be addressed to Zhiqing Meng; mengzhiqing@zjut.edu.cn
}

Received 10 May 2021; Accepted 16 July 2021; Published 30 July 2021

Academic Editor: Daqing Gong

Copyright (C) 2021 Lina Xu and Zhiqing Meng. This is an open access article distributed under the Creative Commons Attribution License, which permits unrestricted use, distribution, and reproduction in any medium, provided the original work is properly cited.

\begin{abstract}
Paid membership system has attracted more and more attention from retailers because of its advantages in improving customer loyalty, increasing repeat purchases and corporate cash flow in the short term, and collecting consumption data conveniently. In the fierce competition environment, it is an interesting topic whether the paid membership card can be accepted by the customers as soon as possible. Based on the theory of evolutionary game, this paper discusses the strategies of retailers to implement the paid membership in the case of two different consumer groups. The results show that only when the relationship between the parameters meets certain conditions can the paid membership card be accepted smoothly. In order to satisfy the condition, retailers should take such measures: making the difference between service level and membership card price bigger and reducing consumers' estimated default risk and retailers' service adjustment factor. The results of this study provide a useful reference for retailers to successfully implement the paid membership system.
\end{abstract}

\section{Introduction}

With the development of information and logistics technology, consumers can search and obtain goods more conveniently. As an intermediate, retailers witness squeezed profits. Moreover, the product homogenization and fierce competition are becoming increasingly obvious. In order to seize more market share and gain more profits, various marketing models are emerging. More and more retailers adopt membership to enhance customer contact, thereby increasing their profits and value $[1,2]$. Costco, Sam's Club, BJ's, and Amazon have already successfully implemented paid membership system and brought consistent and steady revenue to their businesses. However, there were still some failures. In November 2016, BILI announced a conversion in China from paid membership to points-based membership, officially declaring the failure of its paid membership system. The key to success or failure is whether the membership system costing a lot of money can be accepted by consumers. The questions that should be answered by retailers include the following: Should the paid membership system be introduced? How to price the membership? What level of service should be provided?
Early literature on retailer membership system mainly focuses on result analysis, i.e., using existing consumption data to analyze the impact of membership on customer behavior. For example, Allaway et al. [3] used membership data to explore customer segmentation behavior. Leenheer et al. [4] studied the impact of membership program on customer loyalty and estimated models both for the membership decision and for the effect of membership on share-of-wallet. Meyer-Waarden [5] compared the shopping behaviors of cardholders and noncardholders using threeyear supermarket purchase panel data. They found that shopping frequency, wallet share, and store visits of cardholders were significantly higher than those of noncardholders. However, this is not always the case. Acatrinei and Puiu [6] conducted a questionnaire survey, pointed out that the causality relations between membership program and customers' worth may not be as direct as previously thought, and reminded retail store managers to correctly evaluate the membership program.

Early literature is based on the analysis of customers who are members of retailers. With the increasing acceptance of paid membership cards, more problems show up, such as 
whether to launch membership card program? how to promote membership card program successfully? which have gradually aroused the interests of scholars. Kim and Choi [7] simulated the competition model between a warehouse supermarket and a general one, which provided a good explanation for the existence of membership fee and pointed out that the fixed fee membership of the warehousing supermarket was a competitive strategy against the promotion behavior of the general supermarket. Demoulin and Zidda [8] analyzed the factors that affect whether and how long customers accept a new membership program. Gomez et al. [9] conducted a survey on 600 customers of a Spanish chain supermarket to analyze what personal characteristics of customers contribute to their joining the membership card program. Hutchinson et al. [10] analyzed, from the perspective of marketing, how small and medium-sized retailers can promote smoothly the membership system. Aiming at online retailers, Fang et al. [11] focused on the free delivery service and compared the contingent free shipping policies (CFS) and membershipbased free shipping programs (MFS) and pointed out that even if the revenue from member card fee can never compensate the costs arising from offering free shipping, MFS was still the best choice for retailers because the loss can be recouped.

As a new topic born out of service marketing, literature on retailer paid membership strategy is slightly insufficient. Mainstream research focuses on qualitative discussion and analysis of existing member purchase data. Occasionally, modeling method is used to analyze, based just on the competition strategy between enterprises. Little attention is paid to game theory. As far as we know, this is the first paper that studies paid membership strategy based on customer heterogeneity and focuses on the smooth implementation of the paid member program, adopting the theory of evolutionary game.

\section{Problem Description and Payoff Matrix}

The basic idea of evolutionary game theory is that players carry out repeated game activities, where the assumption of limited rationality and learning ability replaces that of complete rationality in traditional game theory. Limited rationality makes it impossible for both sides of the game to find the optimal equilibrium point in every game, but it is possible to analyze the system in a dynamic framework and describe the development and change of the system more accurately. The core concepts of evolutionary game are replicator dynamics and evolutionary stable strategy (ESS). Replicator dynamic equation is the most widely used selection mechanism equation in evolutionary game theory. Similar to the biological system, the behavior of consumer groups evolves over time in the interaction with external environment changes and internal structural adjustment. From the microlevel, the competition among consumer groups is carried out under uncertainty and limited rationality, and their strategies influence each other's. Therefore, the evolutionary game model consists of repeatedly playing games in each stage.
In the initial stage, the retailer determines the membership card price $P$ and the corresponding membership service policy as per market competition environment and its own historical data. Suppose cost of tangible service (such as discounts and free shipping) and intangible service (such as exclusive customer service and return or exchange without reasons) can be recognized as an amount $S$; here $S>P$ is assumed according to the rational assumption of customers. This assumption is reasonable, because customers will buy membership cards only if the benefits outweigh the costs. However, customers who hold membership cards will bring additional benefits to retailers due to their increasing loyalty and purchase volume, more consumption data contribution, and a short-term cash inflow. As long as the benefits can make up for the loss of $S-P$, retailers will be profitable. This is a win-win situation, as seen in Costa, Sam's Club, etc.

It is assumed that the existing customers of the retailer can be divided into two groups: high-value customer group $H$ and low-value customer group $L$. Customers can choose to buy membership cards and then make purchases, or they can choose to give up the preferential treatment and service of membership and purchase directly. Assuming that the same types of customers are homogeneous, the same-type customers' purchase choices are consistent; that is, high-value customers $H$ all choose to pay for the membership card or not and vice versa.

It is generally accepted that the difference between $S$ and $P$ is the main decision-making factor for consumers to decide whether to purchase membership card. However, the purchase of membership card is different from the traditional delivery versus payment mode. Its feature is "fee first goods later"; that is, the consumer pays the membership card fee to the retailer first and does not complete the whole consumption process immediately, but gets member services at intervals or in batches later. This kind of consumption mode determines that consumers are in a disadvantageous position in the transaction process, and they cannot quit halfway. Consumers may bear the risk $(r)$ of the retailer's failure to comply with the contract. The value of $r$ is determined by the customers' own judgment based on some information, such as the enterprise's duration, brand awareness and reputation, whether there are negative news reports or not, and historical performance records. We assume the risk $r$ is symmetric information, that is, information known to both the consumer and the retailer. In addition, if a customer does not join the membership system, there is no such loss for him/her.

In reality, although there is a publicly announced service level $S$, for the retailer there is a lot of room to manoeuvre membership services (such as controlling the percentage of products participating in promotional activities and providing exclusive benefits for members from time to time) because of the lag and long-term membership service. It is hard for any single consumer to accurately predict the service level of membership card. If only customer $H$ pays for the membership card, in order to increase the retention rate of this group because of its high consumption ability and significant contribution to the enterprise performance, the 
retailer will provide high-level member service $S_{h}=(1+k) S$. If customer $L$ pays for the membership card, the retailer will provide the low-level member service $S_{l}=(1-k) S$. If all potential customers buy, retailer will provide average level of member service $S$. $k$ is defined as the retailer's service adjustment factor and $0 \leq k \leq 1$. Suppose that the probability of high-value customer $H$ to buy membership card is $\alpha$ with the probability of not buying $1-\alpha$; the probability of low-value customer $L$ purchasing membership card is $\beta$ with the probability of not buying being $1-\beta$, and $\alpha, \beta \in[0,1]$.

After the two heterogeneous customer groups decide whether to purchase membership card based on weighing the benefits (i.e., enjoying member services) against the costs (such as membership card fee and loss by default), there are four equilibrium states as follows:

(i) State A: both customers $H$ and $L$ choose to purchase membership card, and the retailer provides member service $S$

(ii) State B: customer $H$ chooses to buy, while customer $L$ chooses not to buy, and the retailer provides membership service $S_{h}=(1+k) S$

(iii) State C: customer $H$ chooses not to buy, while customer $L$ chooses to buy, and the retailer provides membership service $S_{l}=(1-k) S$

(iv) State D: both customers $H$ and $L$ choose not to purchase the membership card, and the retailer does not provide membership service

Based on the above, the payoff matrix is established as shown in Table 1.

This part first makes a simple exposition of the basic theory of evolutionary game, then elaborates the problems studied in detail, and explains the meaning of the relevant parameters. On this basis, it finally lists the four possible equilibrium states and derives the payoff matrix.

Next the evolution process of decision-making behavior of the two consumer types after the retailer introduces the membership card system, as well as the final evolutionary stability strategy, will be analyzed. The ultimate goal is to help retailers solve the problem of determining the relationship between membership card price and member service level, which is of great significance in increasing the number of customers who buy membership card and carrying out the paid membership card system successfully.

\section{Analysis of the Evolutionary Game Model}

3.1. Equilibrium Point of the Evolution. In order to construct the evolutionary game model, it is necessary to first establish an evolutionary game system. The expected revenues of consumers $H$ and $L$ are $E_{m}(H)$ and $E_{m}(L)$, respectively, when they buy membership cards. If they do not buy membership cards, the expected revenues become $E_{n}(H)$ and $E_{n}(L)$, respectively. The average expected returns are $E(H)$ and $E(L)$, respectively.

When consumers $H$ and $L$ buy membership cards, their expected returns, respectively, are

$$
\begin{aligned}
E_{m}(H) & =\beta(S-P-r)+(1-\beta)((1+k) S-P-r) \\
& =(1+k) S-P-r-k S \beta, \\
E_{m}(L) & =\alpha(S-P-r)+(1-\alpha)((1-k) S-P-r) \\
& =(1-k) S-P-r+k S \alpha .
\end{aligned}
$$

When consumers $H$ and $L$ do not buy membership cards, their expected returns, respectively, are

$$
\begin{aligned}
E_{n}(H) & =\beta(P-(1-k) S)+(1-\beta)(P-S)=k S \beta+P-S, \\
E_{n}(L) & =\alpha(P-(1+k) S)+(1-\alpha)(P-S)=P-S-k S \alpha .
\end{aligned}
$$

The average expected returns of consumers $H$ and $L$, respectively, are

$$
\begin{aligned}
E(H) & =\alpha E_{m}(H)+(1-\alpha) E_{n}(H) \\
& =\alpha[(2+k) S-2 P-r]+k S(1-2 \alpha) \beta+P-S, \\
E(L) & =\beta E_{m}(L)+(1-\beta) E_{n}(L) \\
& =\beta[(2-k) S-2 P-r]-k S(1-2 \beta) \alpha+P-S .
\end{aligned}
$$

Thus, the replication dynamic equations of consumers $H$ and $L$, respectively, are

$$
\begin{aligned}
F(H) & =\frac{\mathrm{d} \alpha}{\mathrm{d} t}=\alpha\left[E_{m}(H)-E(H)\right] \\
& =\alpha(1-\alpha)[(2+k) S-2 P-r-2 k S \beta], \\
F(L) & =\frac{\mathrm{d} \beta}{\mathrm{d} t}=\beta\left[E_{m}(L)-E(L)\right] \\
& =\beta(1-\beta)[(2-k) S-2 P-r+2 k S \alpha] .
\end{aligned}
$$

From (4) and (5), differential equations, a two-dimensional dynamic system is obtained:

$$
\left\{\begin{array}{l}
F(H)=\frac{\mathrm{d} \alpha}{\mathrm{d} t}=\alpha(1-\alpha)[(2+k) S-2 P-r-2 k S \beta], \\
F(L)=\frac{\mathrm{d} \beta}{\mathrm{d} t}=\beta(1-\beta)[(2-k) S-2 P-r+2 k S \alpha] .
\end{array}\right.
$$

Proposition 1. The stable points of the system are $(0,0),(0$, $1),(1,0)$, and $(1,1)$. When $((2-k) S-r) / 2<P<$ $((2+k) S-r) / 2,\left(\alpha^{*}, \beta^{*}\right)$ is also the stable point, and $\alpha^{*}=$ $(2 P+r-(2-k) S) / 2 k S$ and $\beta^{*}=((2+k) S-2 P-r) / 2 k S$.

Proof. According to (6), let $(\mathrm{d} \alpha / \mathrm{d} t)=0$ and $(\mathrm{d} \beta / \mathrm{d} t)=0$, respectively; it is obvious that $(0,0),(0,1),(1,0)$, and $(1,1)$ are the stable points of the system. When $((2-k) S-r) / 2<P<((2-k) S-r) / 2$, we have $0<(2 P+r-$ $(2-k) S) / 2 k S<1$ and $0<((2+k) S-2 P-r) / 2 k S<1$; in this case, $\left(\alpha^{*}, \beta^{*}\right)$ is also the stable point of the system.

3.2. Stability Analysis of the Equilibrium Point. We can analyze the local stability of the Jacobian matrix of the system [12]. For the differential equation (6), take the partial 
TABLE 1: The payoff matrix of consumers $H$ and $L$.

\begin{tabular}{lcr}
\hline Consumer $H$ & Purchase $(\beta)$ & Consumer $L$ \\
& $(S-P-r, S-P-r)$ & No purchase $(1-\beta)$ \\
\hline Purchase $(\alpha)$ & $(P-(1-k) S,(1-k) S-P-r)$ & $((1+k) S-P-r, P-(1+k) S)$ \\
No purchase $(1-\alpha)$ & $(P-S, P-S)$ & $(1-P)$ \\
\hline
\end{tabular}

derivatives of $\alpha$ and $\beta$, respectively, to get the Jacobian matrix:

$$
\begin{aligned}
J & =\left[\begin{array}{cc}
\frac{\partial F(H)}{\partial \alpha} & \frac{\partial F(H)}{\partial \beta} \\
\frac{\partial F(L)}{\partial \alpha} & \frac{\partial F(L)}{\partial \beta}
\end{array}\right] \\
= & {\left[\begin{array}{cc}
(1-2 \alpha)[(2+k) S-2 P-r-2 k S \beta] & -2 k S \alpha(1-\alpha) \\
2 k S \beta(1-\beta) & (1-2 \beta)[(2-k) S-2 P-r+2 k S \alpha]
\end{array}\right] . }
\end{aligned}
$$

The determinant condition $\operatorname{det} J$ and trace condition $\operatorname{tr} J$ of Jacobian matrix are, respectively, as follows:

$$
\begin{aligned}
\operatorname{det} J= & (1-2 \alpha)(1-2 \beta)[(2+k) S-2 P-r-2 k S \beta] \\
& {[(2-k) S-2 P-r+2 k S \alpha]+4 k^{2} S^{2} \alpha \beta(1-\alpha)(1-\beta), } \\
\operatorname{tr} J= & (1-2 \alpha)[(2+k) S-2 P-r-2 k S \beta]+ \\
& (1-2 \beta)[(2-k) S-2 P-r+2 k S \alpha] .
\end{aligned}
$$

If $\operatorname{det} J>0$ and $\operatorname{tr} J<0$ are satisfied, the stable point of the dynamic equation is an evolutionary stable strategy (ESS), which reflects the stable state of the evolution of consumer groups.

Proposition 2. If $P>((2+k) S-r) / 2,(0,0)$ is the ESS point, $(1,0)$ and $(0,1)$ are saddle points and $(1,1)$ is the instability point. That is, if the membership card price exceeds a certain value, both types of consumers choose not to buy.

Proof. The Jacobian matrix of the system is calculated and the conclusion is shown in Table 2.

The evolution phase diagram is shown in Figure 1.

We show that when $P>((2+k) S-r) / 2$, both high-value customers $H$ and low-value customers $L$ tend not to buy membership cards. That is to say, when other parameters are given, the price of membership card is too high, or the membership price is given while the service level is low and the risk of nonperformance is high, both customer groups choose not to buy, or customers who have already bought decide not to buy in the following cycle.

Proposition 3. If $((2-k) S-r) / 2<P<((2+k) S-r) / 2$, the system has no ESS point. $(0,0),(1,0),(0,1),(1,1)$ are saddle points, and $\left(\alpha^{*}, \beta^{*}\right)$ is the unstable point; that is, there is no evolutionary stable strategy.

Proof. The Jacobian matrix of the system is calculated and the conclusion is shown in Table 3.

From Proposition 3, if the price of the membership card is set within an interval $k S$, i.e., when other conditions are set, the price of the membership card is neither too high nor too low, and then there will be no stable state of consumers' purchasing behavior. That is to say, as time goes on, the purchasing behaviors of the two consumers groups are constantly changing. Under this situation, it is difficult for retailers to estimate consumers' behavior and take appropriate measures in advance. Retailers should not fix a price within this range to avoid wasting human and other resources.

Proposition 4. If $P<((2-k) S-r) / 2,(1,1)$ is the ESS point, $(1,0)$ and $(0,1)$ are saddle points and $(0,0)$ is the instability point. That is, if the membership card price is lower than a certain value, both consumer groups choose to buy.

Proof. The Jacobian matrix of the system is calculated and the conclusion is shown in Table 4.

The evolution phase diagram is shown in Figure 2.

According to Proposition 4, if the membership card price is below a certain value, both types of consumers choose to buy. Obviously, the following corollary can be obtained from the condition of $P<((2-k) S-r) / 2$.

Corollary 1. Under a given service level $S$, card price $P$, and default loss $r$, retailers should reduce their service adjustment factor $k$ as much as possible in order to increase the possibility of reaching $(1,1)$ equilibrium point. 
TABLE 2: Stability of stable points when $P>((2+k) S-r) / 2$.

\begin{tabular}{|c|c|c|c|c|c|}
\hline Stable point & $\operatorname{det} J$ & & $\operatorname{tr} J$ & & Local stability \\
\hline$O(0,0)$ & {$[(2+k) S-2 P-r][(2-k) S-2 P-r]$} & + & $4 S-4 P-2 r$ & - & ESS \\
\hline$X(1,0)$ & $-[(2+k) S-2 P-r]^{2}$ & - & 0 & 0 & Saddle point \\
\hline$Y(0,1)$ & $-[(2-k) S-2 P-r]^{2}$ & - & 0 & 0 & Saddle point \\
\hline$Z(1,1)$ & {$[(2+k) S-2 P-r][(2-k) S-2 P-r]$} & + & $4 P+2 r-4 S$ & + & Instability point \\
\hline
\end{tabular}

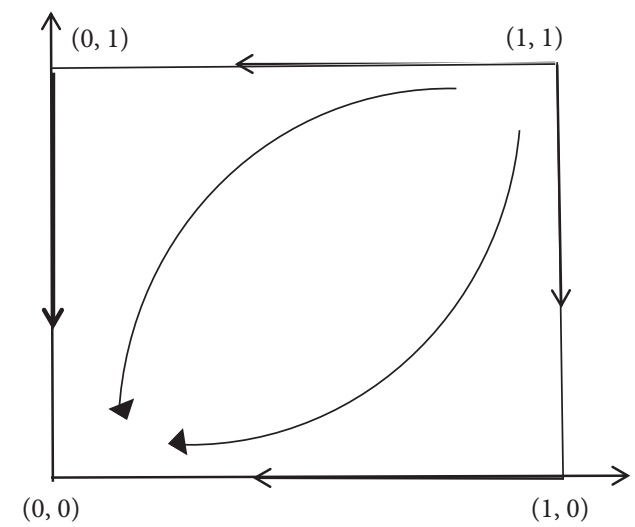

Figure 1: Dynamic diagram of evolution phase when $P>((2+k) S-r) / 2$.

TABLE 3: Stability of stable points when $((2-k) S-r) / 2<P<((2-k) S-r) / 2$.

\begin{tabular}{|c|c|c|c|c|c|}
\hline Stable point & $\operatorname{det} J$ & & $\operatorname{tr} J$ & & Local stability \\
\hline $\mathrm{O}(0,0)$ & {$[(2+k) S-2 P-r][(2-k) S-2 P-r]$} & - & $4 S-4 P-2 r$ & \pm & Saddle point \\
\hline$X(1,0)$ & $-[(2+k) S-2 P-r]^{2}$ & - & 0 & 0 & Saddle point \\
\hline$Y(0,1)$ & $-[(2-k) S-2 P-r]^{2}$ & - & 0 & 0 & Saddle point \\
\hline$Z(1,1)$ & {$[(2+k) S-2 P-r][(2-k) S-2 P-r]$} & - & $4 P+2 r-4 S$ & \pm & Saddle point \\
\hline$P\left(\alpha^{*}, \beta^{*}\right)$ & {$[2 P+r-(2-k) S]^{2}[(2+k) S-2 P-r]^{2} / 4 k^{2} S^{2}$} & + & 0 & 0 & Instability point \\
\hline
\end{tabular}

TABLE 4: Stability of stable points when $P<((2-k) S-r) / 2$.

\begin{tabular}{lcccc}
\hline Stable point & det $J$ & & $\operatorname{tr} J$ & Local stability \\
\hline$O(0,0)$ & {$[(2+k) S-2 P-r][(2-k) S-2 P-r]$} & + & $4 S-4 P-2 r$ & + \\
$X(1,0)$ & $-[(2+k) S-2 P-r]^{2}$ & - & 0 & Instability point \\
$Y(0,1)$ & $-[(2-k) S-2 P-r]^{2}$ & - & 0 & Saddle point \\
$Z(1,1)$ & {$[(2+k) S-2 P-r][(2-k) S-2 P-r]$} & + & $4 P+2 r-4 S$ & - \\
\hline
\end{tabular}

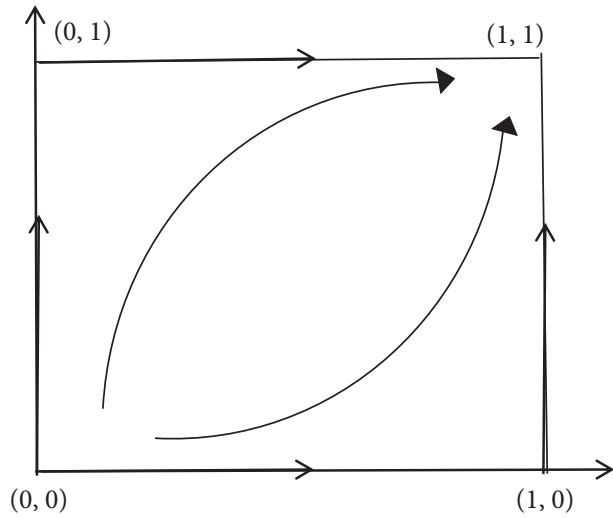

Figure 2: Dynamic diagram of evolution phase when $P<((2-k) S-r) / 2$.
For consumers, the smaller the service adjustment factor $k$ means the lower the variance in retailer's service level, which also indicates a smaller risk of accepting retailer's membership service. Then consumer membership card purchase ratio will naturally increase, and it is easier to reach the equilibrium state of $(1,1)$.

This section analyzes the evolutionary game model on the basis of the second part. First of all, according to the replication dynamic equation to construct a two-dimensional dynamic system, the five equilibrium points of this system are obtained (Proposition 1). Secondly, calculate the determinant and trace condition of Jacobian matrix of the system, and then the local stability of the five equilibrium points is judged in three cases (Propositions 2-4); the corresponding evolution phase diagrams are also been 
drawn (Figures 1-2). Finally, the conditions for achieving the $(1,1)$ stable equilibrium point are further inferred (Corollary 1).

\section{Numerical Analysis}

In order to deeply understand the dynamic process of purchase decision on the retailer paid membership card of two heterogeneous customer groups under different conditions, as well as the retailer's coping strategies, MATLAB was used to simulate the evolution process:

(1) Take the parameters $S=100, P=80, k=0.2$, and $r=70$, which satisfies the condition of $P>((2+$ $k) S-r) / 2$ in Proposition 2. The results are shown in Figure 3.

From Figure 3(a), when the card price is too high, or given the price of membership card, due to the low member service level and high estimated default risk because of retailer's poor reputation, consumers are cautious about buying membership cards. No matter what the initial purchase probability is, as time goes on, giving up purchase will be the final choice, and $(0,0)$ is the evolutionary stable strategy.

From Figure 3(b), after weighing costs and benefits to avoid unexpected losses, customers $H$ and $L$ will choose not to buy membership cards after a short period of gaming. And in the case of high card price, taking $\alpha=\beta=0.1$ as the cut-off point, when the purchase probability is higher than 0.1 , the decrease rate of purchase probability of customer $H$ is greater than that of customer $L$. If the purchase probability of both parties is lower than 0.1, under the expectation that retailers are more likely to provide highlevel membership services, the decrease rate of customer $H$ is more slowly than that of customer $L$. This conclusion also conforms to the hypothesis of high value expected by consumer $H$. However, after repeated disappointment due to low service level and default loss, customers $H$ and $L$ give up buying membership cards in the end.

(2) Take the parameters $S=100, P=80, k=0.2$, $r=50$, which satisfies the condition of $((2-k) S-$ $r) / 2<P<((2+k) S-r) / 2$ in Proposition 3. The results are shown in Figure 4.

From Figure 4(a), when the membership card price is at a medium level, there is no stable evolution strategy for the system. Figure 4(a) shows that the system evolves continuously centering on the point $\left(\alpha^{*}, \beta^{*}\right)$. Figure 4(b) shows that, in general, the purchase probability of customer $H$ is higher than that of customer $L$, which also verifies the hypothesis of high value expected by customer $H$. In this case, the membership card price is not too high for customer $H$. When the initial purchase probability is low, with time passing, the purchase probability of customer $H$ increases gradually, which is infinitely close to 1 . At the same time, the probability of retailer providing higher level membership card service is also higher. However, because the retailer fails to fulfill the contracted obligations, customers $H$ suffers the loss and their purchase enthusiasm begins to decrease, then the purchase probability drops to the initial point, and then the cycle starts all over again. Customer $L$, on the contrary, at the very beginning, thinks the price of membership card is a little expensive, which inhibits the desire to buy. The purchase probability rapidly drops to a position close to 0 . However, with the increasing probability of retailer providing high-level membership services, the purchasing enthusiasm is constantly stimulated to a certain extent (about 0.8 as estimated by Figure 4(b)) because of yearning for the preferential treatments. But the risk from retailers is constantly showing up, so the probability of purchase is declining, after which the circle starts all over again.

(3) Take the parameters $S=100, P=80, k=0.2$, $r=10$, which satisfies the condition of $P<\quad((2-$ $k) S-r) / 2$ in Proposition 4. The results are shown in Figure 5.

From Figure 5(a), when the membership card price is right, the retailer has the strength to provide high-level service or has excellent reputation that makes the expected risk of default low. Regardless of the initial purchase probability of customers $H$ and $L,(1,1)$ will eventually be the evolutionary stable strategy over time. That is, after weighing the cost and benefit to avoid losing the right to enjoy member services at a reasonable price, after a short period of game, customers $H$ and $L$ will choose to buy membership cards.

Figure 5(b) shows that, in the case of $P<((2-k) S-r) / 2, \alpha=\beta=0.8$ is the critical point. When the purchase probability is lower than 0.8 , the growth rate of the purchase probability of customer $H$ is higher than that of customer $L$. However, if the purchase probability of both parties is higher than 0.8 , under the stimulation that retailers are more likely to provide high-level member services, the growth rate of purchase probability of customer $L$ is much higher than that of customer $H$. In this case, the possibility of retailer providing low-level member services increases, and customer $H$ is restrained. But the gap between the service level and the price of the membership card is not so small that he/she wants to give it up. Through constant game adjustment, in the end, customers $H$ and $L$ buy membership cards, and retailers provide average level of membership services for both groups.

(4) Take the parameters $S=100, P=80, r=10$, which satisfies the condition of $P<((2-k) S-r) / 2$ in Proposition 4. Under the premise, the effects of different service adjustment factors $k$ are analyzed, taking $k=0.25,0.15,0.05$, respectively. The results are shown in Figure 6.

As shown in Figure 6, when $k=0.25$, the system reaches the evolutionary stability strategy of $(1,1)$ at about $t=0.75$; 


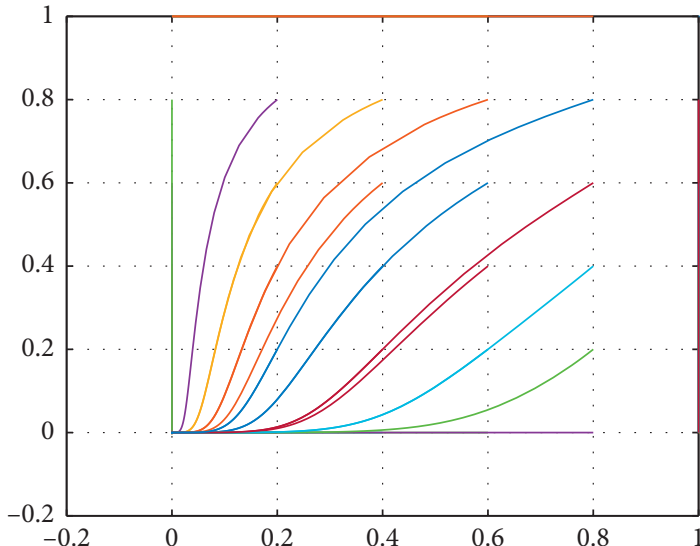

(a)

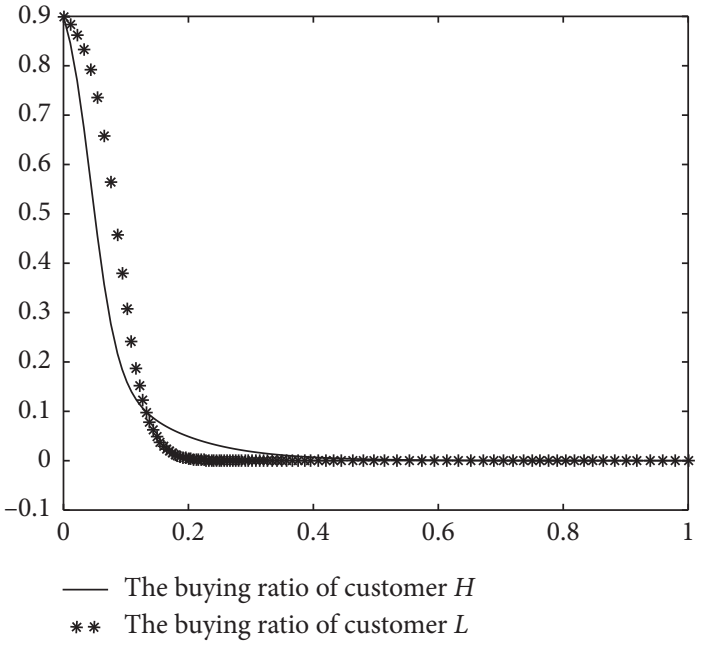

(b)

Figure 3: (a) ESS at $P>((2+k) S-r) / 2$. (b) System evolution at $P>((2+k) S-r) / 2$.

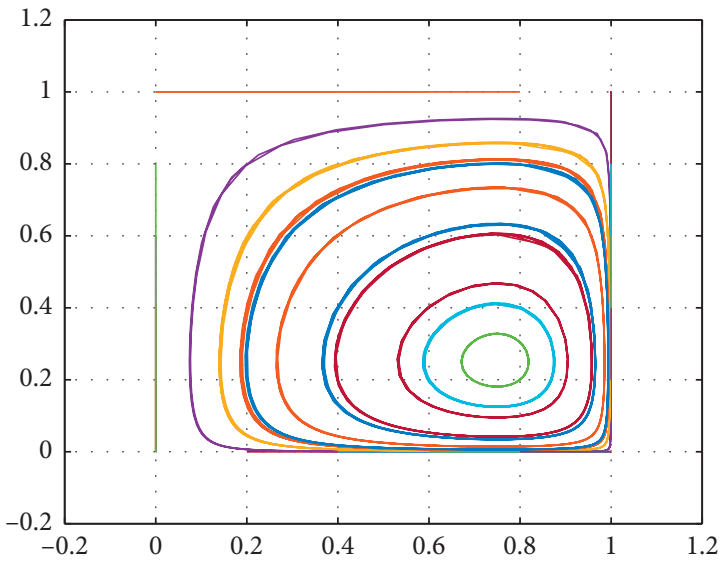

(a)

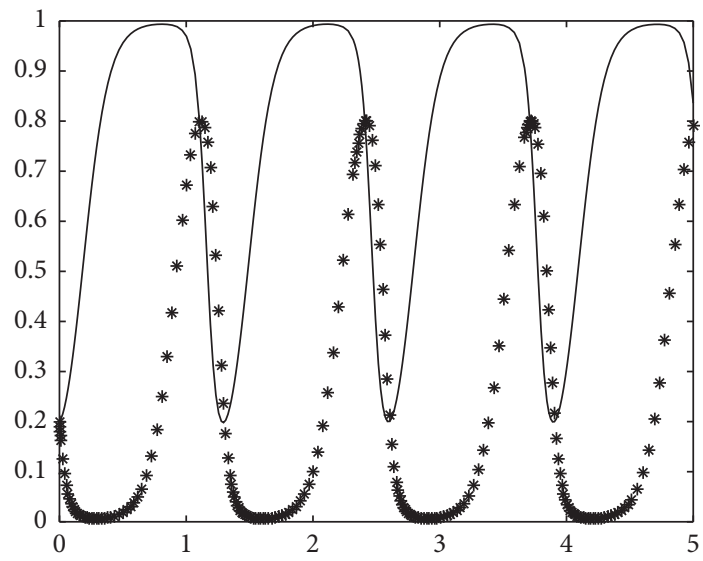

(b)

FIgURe 4: (a) ESS at $((2-k) S-r) / 2<P<((2-k) S-r) / 2$. (b) System evolution at $((2-k) S-r) / 2<P<((2-k) S-r) / 2$.

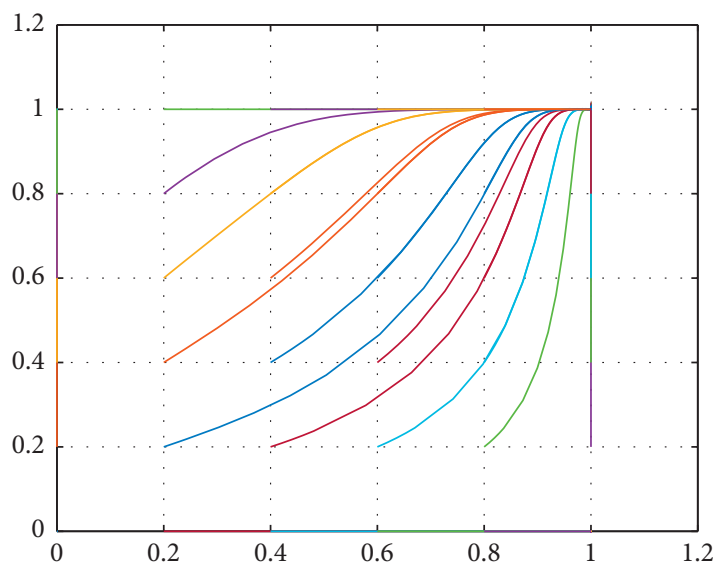

(a)

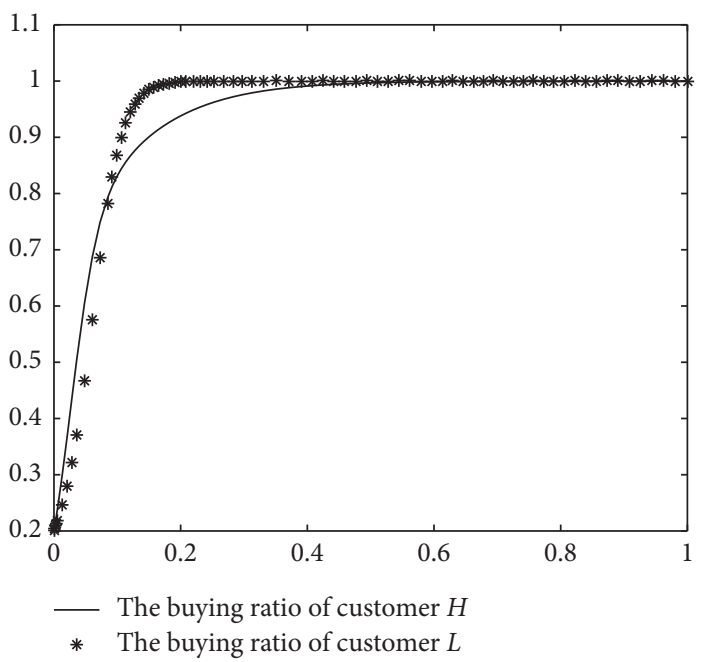

(b)

Figure 5: (a) ESS at $P<((2-k) S-r) / 2$. (b) System evolution at $P<((2-k) S-r) / 2$. 


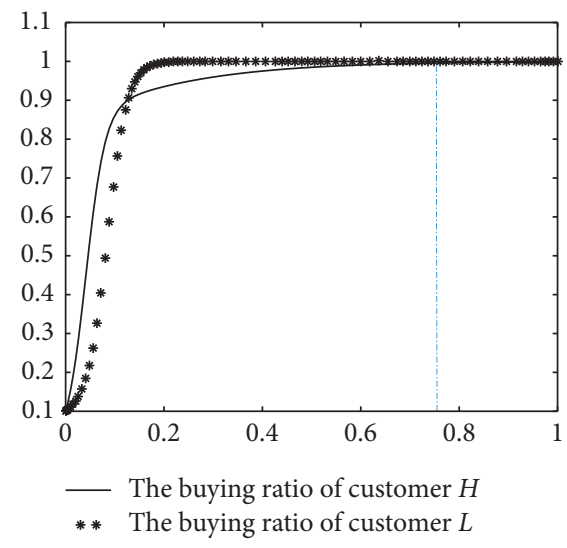

(a)

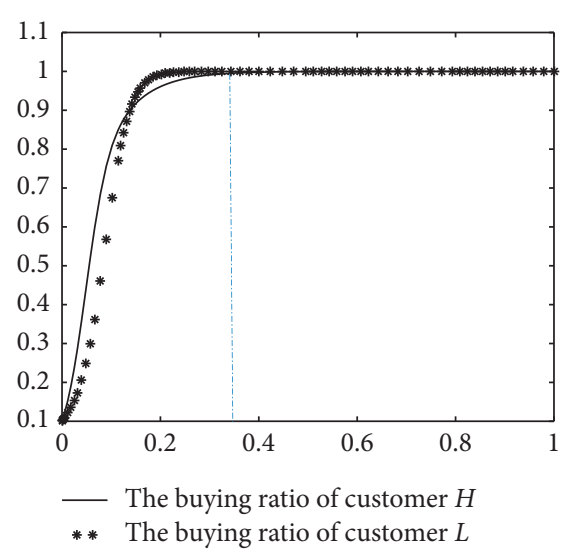

(b)

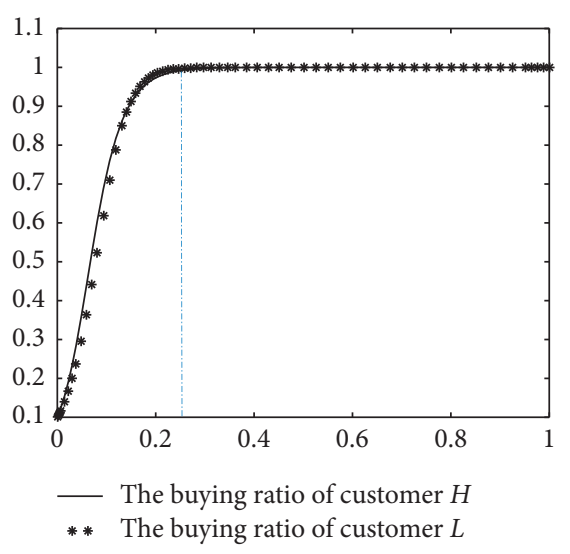

(c)

FIGURE 6: System evolution at different values of $k$ under the premise of $P<((2-k) S-r) / 2$. (a) $k=0.25$. (b) $k=0.15$. (c) $k=0.05$.

$k=0.15$, at about $t=0.35 ; k=0.05$ at about $t=0.25$. This also validates the conclusion of Corollary 1.

In this section, MATLAB is used to carry out a strict numerical simulation calculation on the propositions and corollary in the third part to verify them. Furthermore, from the above graphics, the actual operation of retailers is carefully analyzed and some interesting conclusions are drawn. The numerical simulation analysis vividly shows the dynamic evolution process of the purchasing behavior of paid membership cards of two customer groups, which allows us to directly observe the change in behavior process of customers $H$ and $L$, the noteworthy turning points, and the final equilibrium states. In addition, the simulation also verifies the hypothesis for high-value and low-value customers from a different perspective.

\section{Conclusion}

This paper, based on the premise that retailers intend to launch paid membership, considers the two customer groups: high-value and low-value. The evolutionary game model is constructed, and the evolutionary stability strategies in different situations are obtained. Combined with numerical examples, it is clear that the key factors affecting the consumer evolutionary stability strategy include card price, estimated default loss, service level, and retailer's service adjustment factor. Retailers can achieve their goals of successfully implementing membership card program by making efforts in these aspects.

The conclusion of this paper has the following enlightening significance:

(1) Help retailers assess whether it is the right time to introduce a membership card program. Retailers should first judge the relationship between various parameters based on known data. If they meet the condition of $P<((2-k) S-r) / 2$, it can be launched. Otherwise, they had better not, at least temporarily, which avoids unnecessary waste of resources.

(2) Provide a feasible path for retailers to successfully implement a paid membership card program. On the one hand, make the difference between membership service and membership card price as big as possible. Although it seems that the gain outweighs the loss, in the long run, it can still bring potential benefits to the enterprise [11]. On the other hand, given services and card prices, retailers should try to reduce their service adjustment factors, that is, to provide consumers with a more transparent membership system, reducing the space for human manipulation. This also shows that no matter in any business field, being honest with your customers is always the only way to success.

The research here is only a small step forward in this field. There are still some limitations. For example, it is assumed that all customers have the same perception of member services and products. In fact, customers of high and low value may have different perceptions, which will be left for later. Further research can consider the heterogeneity of consumer value perception, the retailer's revenue analysis, and the game relationship between retailers and customers in these new situations. The author and her team will continue to advance on the path and hope to have some beneficial enlightenment for the development of retail industry.

\section{Data Availability}

The data used to support the findings of this study are included within the article.

\section{Conflicts of Interest}

The authors declare that they have no conflicts of interest.

\section{Acknowledgments}

This work was supported by the National Natural Science Foundation of China (grant no. 11871434) and the Natural Science Foundation of Zhejiang Province (grant no. LY18A010031). 


\section{References}

[1] L. Meyer-Waarden, "The effects of loyalty programs on customer lifetime duration and share of wallet," Journal of Retailing, vol. 83, no. 2, pp. 223-236, 2007.

[2] J. Leenheer and T. H. A. Bijmolt, "Which retailers adopt a loyalty program? an empirical study," Journal of Retailing and Consumer Services, vol. 15, no. 6, pp. 429-442, 2008.

[3] A. W. Allaway, R. M. Gooner, D. Berkowitz, and L. Davis, "Deriving and exploring behavior behavior segments within a retail loyalty card program," European Journal of Marketing, vol. 40, no. 11-12, pp. 1317-1339, 2006.

[4] J. Leenheer, H. J. van Heerde, T. H. A. Bijmolt, and A. Smidts, "Do loyalty programs really enhance behavioral loyalty? an empirical analysis accounting for self-selecting members," International Journal of Research in Marketing, vol. 24, no. 1, pp. 31-47, 2007.

[5] L. Meyer-Waarden, "The influence of loyalty programme membership on customer purchase behaviour," European Journal of Marketing, vol. 42, no. 1-2, pp. 87-114, 2008.

[6] C. Acatrinei and T. V. Puiu, "The loyalty card: issues in evaluating loyalty program effectiveness," International Journal of Economic Practices and Theories, vol. 2, no. 3, pp. 153-164, 2012.

[7] S.-H. Kim and S. C. Choi, "The role of warehouse club membership fee in retail competition," Journal of Retailing, vol. 83, no. 2, pp. 171-181, 2007.

[8] N. T. M. Demoulin and P. Zidda, "Drivers of customers' adoption and adoption timing of a new loyalty card in the grocery retail market," Journal of Retailing, vol. 85, no. 3, pp. 391-405, 2009.

[9] B. García Gómez, A. M. Gutiérrez Arranz, and J. Gutiérrez Cillán, "Drivers of customer likelihood to join grocery retail loyalty programs. an analysis of reward programs and loyalty cards," Journal of Retailing and Consumer Services, vol. 19, no. 5, pp. 492-500, 2012.

[10] K. Hutchinson, L. V. Donnell, A. Gilmore, and A. Reid, "Loyalty card adoption in sme retailers: the impact upon marketing management," European Journal of Marketing, vol. 49, no. 3-4, pp. 467-490, 2015.

[11] Z. Fang, Y. C. C. Ho, X. Tan, and Y. Tan, "Show me the money: the economic impact of membership-based free shipping programs on e-tailers," Information Systems Research, https:// www.researchgate.net/publication/346668107, 2020.

[12] D. Friedman, "Evolutionary games in economics," Econometrica, vol. 59, no. 3, pp. 637-666, 1991. 